\title{
Changing proportions of paucibacillary leprosy cases in global leprosy case notification
}

\author{
C. R. Butlin ${ }^{\mathrm{a}}$ \& D. N. J. Lockwood ${ }^{\mathrm{b}}$ \\ ${ }^{a}$ Research volunteer, The Leprosy Mission England \& Wales, UK \\ ${ }^{\mathrm{b}}$ Professor, London School of Hygiene and Tropical Medicine, UK
}

Submitted 6 July 2020; Accepted 10 August 2020

\begin{abstract}
Summary
Objectives: Classification of new cases of leprosy into Paucibacillary (PB) or Multibacillary (MB) groups is important as it determines the duration of the treatment regimen, and predicts both complications of leprosy and risk of infection to contacts. Criteria have changed over the past 4 decades. We studied the published global leprosy statistics to reveal any major temporal changes in the proportion of $\mathrm{PB}$ cases.

Results: Global data published by WHO over the past 40 years demonstrate a continuous decrease in the proportion of newly reported leprosy cases who are classified as paucibacillary $(\mathrm{PB})$ from nearly $80 \%$ to around $40 \%$. Independent validation of consistent and accurate classification is lacking.

Conclusions: The decrease in PB proportion may be an artefactual, rather than an epidemiological, phenomenon. Whilst it is impossible to be certain, we suspect that a combination of changes in criteria and "overclassifying" to the MB group by field staff is the cause.
\end{abstract}

Keywords: Paucibacillary leprosy, classification, case detection, global leprosy situation

\section{Introduction}

Leprosy patients present with clinical disease that encompasses a range of skin lesions and nerve involvement. This reflects the different immune responses that patients mount to Mycobacterium leprae (or M lepromatosis). Several different classification schemes have been used to facilitate grouping patients with similar disease types together. The clinical diagnosis of leprosy is made from the clinical appearance of skin lesions, thickened peripheral nerves and looking for acid fast bacilli in slit skin smears. Patients can be assigned to a clinical type of disease. The Ridley-Jopling scale was developed to enable grouping of patients, determine duration of treatment and predict clinical outcomes, such as reactions. ${ }^{1}$ This spectrum ranges from polar tuberculoid (TT) through borderline tuberculoid (BT), mid-borderline (BB), borderline lepromatous (BL) and polar lepromatous (LL). To make classification (for treatment) operationally easier for leprosy field staff in the light of recommendations for routine use of

Correspondence to: C.R. Butlin, 42 Old Drive, Polegate, East Sussex, UK (e-mail: drbutlin@ yahoo.com) 
Table 1. Criteria for leprosy patient classification 1982-98

\begin{tabular}{|c|c|c|c|}
\hline \multirow[t]{2}{*}{ Date } & \multirow[t]{2}{*}{ Reference } & \multicolumn{2}{|c|}{ Advice } \\
\hline & & PB & $\overline{M B}$ \\
\hline 1982 & $\begin{array}{l}\text { WHO, chemotherapy of } \\
\text { leprosy for control } \\
\text { programmes }\end{array}$ & I, TT, BT cases & $\begin{array}{c}\text { LL, BL, BB cases and cases } \\
\text { with smear }>1+\text { at any one site }\end{array}$ \\
\hline 1988 & $\begin{array}{l}\text { WHO expert committee 6th } \\
\text { report }\end{array}$ & I, TT, BT cases & $\begin{array}{l}\mathrm{LL}, \mathrm{BL}, \mathrm{BB} \text { cases and any } \\
\text { cases with positive smear }\end{array}$ \\
\hline 1998 & $\begin{array}{l}\text { WHO expert committee } 7 \text { th } \\
\text { report }\end{array}$ & $\begin{array}{c}\text { Paucibacillary single lesion } \\
\text { leprosy: one skin lesion. } \\
\text { Paucibacillary leprosy: } 2-5 \\
\text { skin lesions }\end{array}$ & $\begin{array}{l}\text { Multibacillary leprosy : more } \\
\text { than } 5 \text { skin lesions and any } \\
\text { cases with positive smear }\end{array}$ \\
\hline
\end{tabular}

multi-drug therapy (MDT), a simpler two-group classification was introduced by the World Health Organization (WHO) in 1982, with patients being allocated to either paucibacillary or multibacillary groups. ${ }^{2}$ These names were based on concept that patients with the different types of leprosy had either few bacteria or many bacteria. The classification of a patient is important because it determines treatment duration, which is currently one year for MB cases and 6 months for PB cases.

The definition used to allocate patients to their category has changed as shown in Table 1. When the concept of $\mathrm{PB} / \mathrm{MB}$ was first introduced ${ }^{2}$ allocation criteria were the patient's Madrid classification or Ridley-Jopling classification, and a case whose skin smear was $1+$ could be considered as PB. In 1988 all smear positive patients were included in the MB group. ${ }^{3}$

To further simplify classification (for treatment) for frontline General Health Workers in resource-constrained leprosy-endemic countries, the recommended method of grouping was changed in 1998 to skin lesion counting. ${ }^{4}$ The WHO Expert Committee suggested the following: paucibacillary single lesion leprosy (one skin lesion); paucibacillary leprosy (2-5 skin lesions); multibacillary leprosy (more than 5 skin lesions). In addition, "single lesion PB" cases were included with other PB cases, defined as having 5 or less skin lesions, ${ }^{4}$ and if the skin smear was positive the patient should be treated with the MB regimen. These different definitions are summarised in Table 1.

We hypothesised that the proportion of PB type amongst newly detected cases had changed over the years. We tested this by collating all the published data on leprosy case numbers and types by the WHO leprosy unit in their annual reports.

\section{Materials and methods}

Most leprosy endemic countries reported annual leprosy statistics to World Health Organisation (WHO) for the past 4 decades. We extracted data from the Weekly Epidemiological Records of $\mathrm{WHO}^{5-24}$ and collated the numbers of leprosy cases treated and their allocation to MB or PB groups for the last 34 years.

The Weekly Epidemiological Record's Global leprosy situation articles contain the previous year's figures for all new cases reported. However, a consistent format has not been used, and in some years new case figures were not disaggregated by leprosy group. The number of countries reporting each year has varied. In most years no data was given for Europe. Occasionally the total new case detection figure published has been revised in the following year, as more 
Table 2. MB and PB cases of leprosy diagnosed between 1985 and 2017

\begin{tabular}{|c|c|c|c|c|}
\hline Year & All new cases & MB new cases & PB new cases & $\mathrm{PB} \%$ \\
\hline $1985^{1}$ & 550224 & 113551 & 436673 & $79.36 \%$ \\
\hline 1986 & 573790 & 119080 & 454710 & $79.25 \%$ \\
\hline 1987 & 595145 & 131294 & 463851 & $77.94 \%$ \\
\hline 1988 & 553597 & 119267 & 434330 & $78.46 \%$ \\
\hline 1989 & 550743 & 123187 & 427556 & $77.63 \%$ \\
\hline 1990 & 571792 & 151622 & 420170 & $73.48 \%$ \\
\hline 1991 & 613016 & 189679 & 423337 & $69.06 \%$ \\
\hline 1992 & 667133 & 225416 & 441717 & $66.21 \%$ \\
\hline 1993 & 615830 & 215640 & 400190 & $64.98 \%$ \\
\hline $1994^{2}$ & 560646 & 195161 & 365485 & $65.19 \%$ \\
\hline 1995 & 529376 & 185017 & 344359 & $65.05 \%$ \\
\hline 1996 & 566567 & 154729 & 411838 & $72.69 \%$ \\
\hline 1997 & 684961 & 239120 & 445841 & $65.09 \%$ \\
\hline $1998^{3}$ & 804357 & 321743 & 482614 & $(60 \%)$ \\
\hline 1999 & 738112 & 295245 & 442867 & $(60 \%)$ \\
\hline 2000 & 719330 & 280539 & 438791 & $61.00 \%$ \\
\hline 2001 & 763262 & 305305 & 457957 & $(60 \%)$ \\
\hline 2002 & 620638 & 248255 & 372383 & $(60 \%)$ \\
\hline 2003 & 514718 & 205887 & 308831 & $(60 \%)$ \\
\hline 2004 & 407791 & 194372 & 213419 & $52.34 \%$ \\
\hline 2005 & 299036 & 158728 & 140308 & $46.92 \%$ \\
\hline 2006 & 259017 & 137409 & 121608 & $46.95 \%$ \\
\hline 2007 & 254525 & 140174 & 114351 & $44.93 \%$ \\
\hline 2008 & 249007 & 140392 & 108615 & $43.62 \%$ \\
\hline 2009 & 244796 & 139125 & 105671 & $43.17 \%$ \\
\hline 2010 & 228474 & 125559 & 102915 & $45.04 \%$ \\
\hline 2011 & 219075 & 125513 & 93562 & $42.71 \%$ \\
\hline 2012 & 232857 & 137410 & 95447 & $40.99 \%$ \\
\hline 2013 & 215656 & 129464 & 86192 & $39.97 \%$ \\
\hline 2014 & 213899 & 126091 & 87808 & $41.05 \%$ \\
\hline 2015 & 210758 & 126783 & 83975 & $39.84 \%$ \\
\hline 2016 & 214783 & 127013 & 87770 & $40.86 \%$ \\
\hline 2017 & 210671 & 125983 & 84688 & $40.20 \%$ \\
\hline Total & 15253582 & 5753753 & 9499829 & $62.28 \%$ \\
\hline
\end{tabular}

Notes: ${ }^{1} 1985-1993$ data is for only highest-burden 32 countries. ${ }^{2} 1994-1999$, PB\% from 32 countries applied to all new cases. ${ }^{3} 1998,1999,2001,2002,2003$, PB cases estimated at $60 \%$ all new cases.

reports were received later. If the revised total did not include the MB/PB proportions, it was not utilised in this paper.

\section{Results}

Since 1985, worldwide, 15,253,582 new leprosy cases have been diagnosed and treated with multidrug therapy (MDT) and reported to the national leprosy programmes. This includes 5,753,753 cases classified as Multibacillary (MB) and 9,499,829 classified as Paucibacillary (PB) leprosy and treated with MDT $^{5-24}$ (Table 2). Most PB patients received dual therapy (rifampicin and dapsone) for 6 months $^{4}$, and some were treated with rifampicin, ofloxacin and minocycline in the single dose regimen for "single lesion leprosy". MB cases were given rifampicin, dapsone and clofazimine, but the recommended duration of therapy changed twice during theis period. 


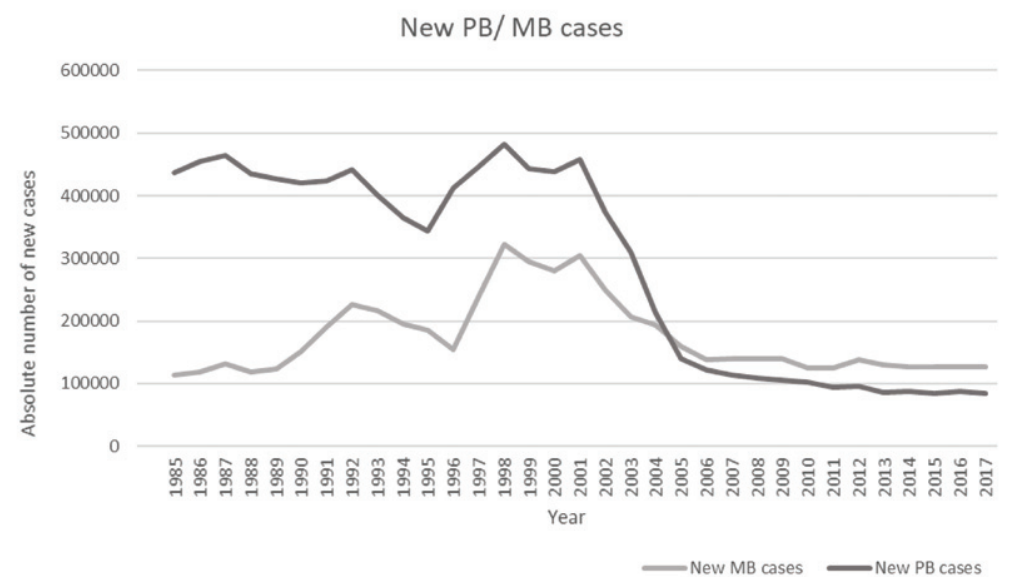

Figure 1 Number of new cases detected each year according to MB/PB grouping.

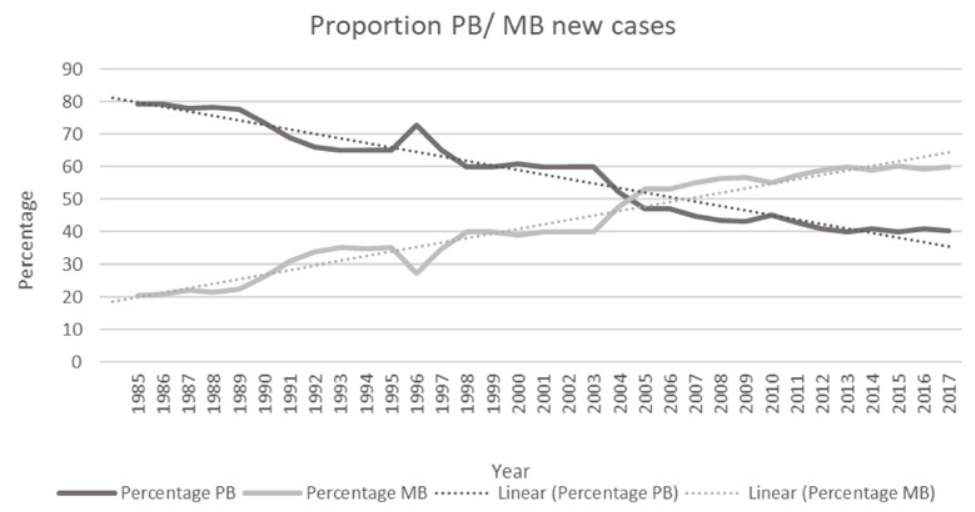

Figure 2 Proportions of MB and PB amongst new cases detected each year.

Figure 1 shows the trend in the annual number of MB and of PB cases. There is a highly significant association between year and number of PB cases $(p<0.001)$ but not between year and number of MB cases $(p=0.294)$. The fall in the number of new PB cases detected is steeper during the period 2000-2005, than at other periods, and compared with the rate of fall in $\mathrm{MB}$ case detection over the same period.

The proportion of PB cases amongst new cases, has altered from nearly $80 \%$ in early years to $40 \%$ since 2012. This shift is gradual, not stepwise, Figure 2 shows proportions with line of best fit.

From 1982 onwards a high proportion of new cases reported has been detected in India. This means that any consistent trend in India will disproportionately affect the global figures.

\section{Discussion}

The consistent and significant shift in case type towards MB cases predominating in the national reports probably results from the interaction of several different effects. These include a changing case definition and perhaps field workers overclassifying MB patients. It is 
probably not a genuine epidemiological difference, though this cannot be discounted since the diagnosis and classification of cases are not routinely validated in all endemic areas.

The period when the rate of fall in new PB case detection appears to be highest, coincides with a time when several countries declared the achievement of "elimination of leprosy as a public health probem". At that time, when active case detection practices by specialized staff were being reduced, perhaps the more obvious and more advanced cases (predominantly MB) were more likely to be detected than PB cases with only inconspicuous skin lesions. The changes are difficult to interpret when there have been regular changes in the case definition for the types of leprosy as Table 1 Illustrates.

There may be bias based on the quality of classification skills amongst the field workers who decide whether the new case is PB or MB. Their decisions in turn often rest on the availability and quality of skin smear services. A lack of skin smear services might be expected to increase the proportion of new cases who are allocated to the PB regimen, but also to reduce the number of early lepromatous cases detected (since these MB cases may have no recognisably thickened nerves and often have no skin patches with impaired sensation) which could also increase the apparent PB proportion. Conceivably, the general health workers with less experience of leprosy who took over responsibility for leprosy diagnosis and treatment after "elimination", may be less efficient at discovering all skin patches when a full body examination is needed, and tend to underestimate the lesion count (overclassifying in the PB category).

Skin lesion counting system is still recommended. ${ }^{25,26}$ Several authoritative publications state that if there is doubt about allocating patients to $\mathrm{PB}$ or to MB groups, the MB regimen should be used, 4,26,27 and this advice may have been widely taken. Field workers lacking confidence in their classification skills might deliberately overuse the MB regimen thinking it will be safer to overtreat PB cases than to risk undertreating MB cases.

Overclassifying patients as MB results in extra expense to programmes and an undue medication burden for thousands of leprosy cases who received MB MDT instead of the simpler PB regimen. Patients who have received the MB regimen with added clofazimine are more likely to be non-compliant than the patients receiving the two-drug regimen. ${ }^{28}$ There have been few studies checking the PB/MB allocation. In one study where clinical and histological diagnoses have been compared in a cohort of 303 patients diagnosed with MB leprosy, the Ridley-Jopling classification of patients was $42.8 \%$ BT, 27.4\% BL, 9.4\% Lepromatous Leprosy (LL), $13.0 \%$ Indeterminate and $7.4 \%$ with non-specific inflammation. This data shows that MB classification is very heterogeneous and encompasses patients with no detectable bacteria and high immunological activity through to patients with high bacterial loads. ${ }^{29}$

It is possible that the clinical phenotype of the MB patient is changing, with people presenting with more skin lesions. This change can only be detected by regular sampling of patient classification with slit skin smears and some biopsies.

The patient classification is an important clinical risk factor. Patients with MB disease are at higher risk of developing nerve damage and reactions, so allocating a patient to the correct classification has important implications for the patient. They will need to be educated about the risk of reactions and nerve damage.

These findings show the need for checks by National Leprosy Programmes and WHO on the accuracy of classification. The staff at WHO are dependent on concerned countries submitting full and accurate information. These issues have been highlighted by others. ${ }^{30,31}$ 


\section{Conclusion}

There has been a remarkable change over time in the global PB proportion amongst new cases as reported by endemic countries and collated by WHO. This is probably due to a change in field level practices, with health workers lowering the threshold over which they will categorise a new case as MB, as well as to the many changes in classification criteria introduced by WHO. The validity of leprosy patient classification should be checked by national leprosy programmes because this is an important clinical and programmatic marker.

\section{Acknowledgements}

Acknowledgement to Emily Quilter for graphs and statistical tests.

\section{Funding}

There was no funding for this study.

\section{Competing interests}

Both authors declare there is no conflict of interest.

\section{Ethical approval}

Not applicable (retrospective study of secondary data).

\section{References}

1 Ridley DS. Histological classification and the immunological aspects of leprosy. Bulletin of World Health Organisation, 1974; 51: 451-465.

2 WHO. 1982, Chemotherapy of leprosy for control programmes: report of a WHO study group. Geneva, World Health Organization, 1982. (WHO Technical Report Series, No. 675).

3 WHO. 1988, WHO Expert Committee on leprosy: sixth report. (WHO Technical Report Series, no. 768).

4 WHO. 1998, WHO Expert Committee on leprosy: seventh report. (WHO Technical Report Series, no. 874).

5 WHO. Leprosy situation in the world in 1997. In: Weekly epidemiological record 1997. vol. 72, (39): 1997; pp. 293-296.

6 WHO. Elimination of leprosy as a public health problem (update). In: Weekly epidemiological record 1998. vol. 73, (40): 1998; pp. 305-312.

7 WHO. Leprosy - Global situation. In: Weekly epidemiological record, 2000. vol. 75, (28): 2000; pp. 225-232.

8 WHO. Leprosy - Global situation. In: Weekly epidemiological record 2000. vol. 75, (34): 2000; p. 280, (correction).

9 WHO. Leprosy. Weekly epidemiological record 2001, vol. 76, (23): 2001; pp. 173-180.

10 WHO. Leprosy. In: Weekly epidemiological record 2002. vol. 77, (1): 2002; pp. 1-8.

11 WHO. Global leprosy situation 2005. In: Weekly epidemiological record 2005. vol. 80, (34): 2005; pp. 289-296.

12 WHO. Global leprosy situation 2006. In: Weekly epidemiological record 2006. vol. 81, (32): 2006; pp. 309-316.

13 WHO. Global leprosy situation 2007. In: Weekly epidemiological record 2007. vol. 82, (25): 2007; pp. 225-232.

14 WHO. Global leprosy situation, beginning 2008. In: Weekly epidemiological record 2008. vol. 83, (33): 2008; pp. 293-300.

15 WHO. Global leprosy situation 2009. In: Weekly epidemiological record 2009. vol. 84, (33): 2009; pp. 333-340.

16 WHO. Global leprosy situation 2010. In: Weekly epidemiological record, 2010. vol. 85, (35): 2010; pp. 337-348.

17 WHO. Leprosy update 2011. In: Weekly epidemiological record 2011. vol. 86, (36): 2011; pp. 389-400.

18 WHO. Global leprosy situation 2012. In: Weekly epidemiological record 2012. vol. 87, (34): 2012; pp. 317-328.

19 WHO. Global leprosy -Update on the 2012 situation. In: Weekly epidemiological record 2013. vol. 88, (35): 2012; pp. 365-380.

20 WHO. Global leprosy update, 2013; reducing disease burden. In: Weekly epidemiological record 2014. vol. 89, (36): 2013; pp. 389-400.

21 WHO. Global leprosy update, 2014: need for early case detection. In: Weekly epidemiological record 2015. vol. 90, (36): 2015; pp. 461-476. 
22 WHO. Global leprosy update, 2015: time for action, accountability and inclusion. In: Weekly epidemiological record 2016. vol. 91, (35): 2015; pp. 405-420.

23 WHO. Global leprosy update, 2016: accelerating reduction of disease burden. In: Weekly epidemiological record 2017. vol. 92, (35): 2016; pp. 501-520.

24 WHO. Global leprosy update, 2017: reducing the disease burden due to leprosy. In: Weekly epidemiological record 2018. vol. 93, (35): 2017; pp. 444-456.

25 WHO. Enhanced Global Strategy for Further Reducing the Disease Burden Due to Leprosy. Operational Guidelines (Updated). SEA-GLP-2009.4 publ. WHO SEARO 2009. 2009.

26 WHO. WHO Expert Committee on leprosy: eighth report. (WHO Technical Report Series; no. 968, 2012).

27 WHO. 1994, Chemotherapy of leprosy: report of a WHO study group. Geneva, World Health Organization, 1994. (WHO Technical Report Series, No. 847).

28 Kumar A, Girdhar A, Chakma JK, Girdhar BK. WHO multidrug therapy for leprosy: epidemiology of default in treatment in Agra district, Uttar Pradesh, India. Biomed Res Int., 2015; 2015: 705804. https://doi.org/10.115 5/2015/705804, PMID: 25705679.

29 Lockwood DNJ, Nicholls P, Smith WCS, Das L, Barkataki P et al. Comparing the Clinical and Histological Diagnosis of Leprosy and Leprosy Reactions in the INFIR Cohort of Indian Patients with Multibacillary Leprosy. PLOS Neglected Tropical Diseases, 2012; 6(6): e1702, https://doi.org/10.1371/journal.pntd.000170 2.

30 Fine PEM. Leprosy's global statistics- still room for improvement. Leprosy Review, 2008; 79: 235-238.

31 deClercq E. Leprosy figures: no time for self-complacency. Leprosy Review, 2012; 83: 3-5. 